EPJ Web of Conferences 77, 00020 (2014)

DOI: $10.1051 /$ epjconf $/ 20147700020$

(C) Owned by the authors, published by EDP Sciences, 2014

\title{
Measuring soot particles from automotive exhaust emissions
}

\author{
Hanspeter Andres ${ }^{1, a}$, Felix Lüönd ${ }^{1}$, Jürg Schlatter ${ }^{1,2}$, Kevin Auderset ${ }^{1}$, Anke Jordan-Gerkens ${ }^{3}$, Andreas Nowak ${ }^{3}$, Volker \\ Ebert $^{3}$, Egbert Buhr ${ }^{3}$, Tobias Klein ${ }^{3}$, Thomas Tuch ${ }^{4}$, Alfred Wiedensohler ${ }^{4}$, Athanasios Mamakos ${ }^{5,6}$, Francesco Riccobono ${ }^{5}$, \\ Kai Discherl ${ }^{7}$, Richard Högström ${ }^{8}$, Jaakko Yli-Ojanperä ${ }^{9}$ and Paul Quincey ${ }^{10}$. \\ ${ }^{1}$ Federal Institute of Metrology (METAS), Lindenweg 50, 3003 Bern-Wabern, Switzerland \\ 2 present address: SBB AG, Infrastructure, Measuring and Diagnostics Technology, 3018 Bern, Switzerland \\ ${ }^{3}$ Physikalisch-Technische Bundesanstalt (PTB), Bundesallee 100, D-38116 Braunschweig, Germany \\ ${ }^{4}$ Leibniz Institute for Tropospheric Research (TROPOS), Permoserstraße 15, D-04318 Leipzig, Germany \\ ${ }^{5}$ Joint Research Center for Energy and Transport (JRC), Via E. Fermi 2749, I-21027 Ispra, Italy \\ ${ }^{6}$ present address: Southwest Research Institute (SwRI), 6220 Culebra Road, San Antonio, TX, United States \\ ${ }^{7}$ Danish Fundamental Metrology (DFM), Matematiktorvet 307, DK-2800 Kongens Lyngby, Denmark \\ ${ }^{8}$ Centre for Metrology and Accreditation (MIKES), Tekniikantie 1, FI-02151 Espoo, Finland \\ ${ }^{9}$ Tampere University of Technology (TUT), Korkeakoulunkatu 3, FI-33101 Tampere, Finland \\ ${ }^{10}$ National Physical Laboratory (NPL), Hampton Road, Teddington, TW11 0LW, United Kingdom
}

\begin{abstract}
The European Metrology Research Programme participating countries and the European Union jointly fund a three year project to address the need of the automotive industry for a metrological sound base for exhaust measurements. The collaborative work on particle emissions involves five European National Metrology Institutes, the Tampere University of Technology, the Joint Research Centre for Energy and Transport and the Leibniz Institute for Tropospheric Research. On one hand, a particle number and size standard for soot particles is aimed for. Eventually this will allow the partners to provide accurate and comparable calibrations of measurement instruments for the type approval of Euro 5b and Euro 6 vehicles. Calibration aerosols of combustion particles, silver and graphite proof partially suitable. Yet, a consensus choice together with instrument manufactures is pending as the aerosol choice considerably affects the number concentration measurement. Furthermore, the consortium issued consistent requirements for novel measuring instruments foreseen to replace today's opacimeters in regulatory periodic emission controls of soot and compared them with European legislative requirements. Four partners are conducting a metrological validation of prototype measurement instruments. The novel instruments base on light scattering, electrical, ionisation chamber and diffusion charging sensors and will be tested at low and high particle concentrations. Results shall allow manufacturers to further improve their instruments to comply with legal requirements.
\end{abstract}

\section{Introduction}

The pollution of particles from automotive-emissions is of particular significance as modern engines with highpressure injection emit a large amount of very very fine particles. They are regarded dangerous for people; in 2012 the World Health Organisation (WHO) classified diesel engine exhaust as carcinogenic to humans.[1] In order to ensure that emissions of ultrafine particulate pollutants (PM $0.1 \mu \mathrm{m}$ and below) can be controlled, the European Commission has introduced a number-based limit value in addition to the mass-based limit value for type approval of Euro 5b and Euro 6 engines.[2] The particle number measurements follow the procedures described in the vehicle emission regulations UN-ECE R49 and R83.[3-4]
Within the project "Emerging requirements for measuring pollutants from automotive exhaust emissions" eleven European organisations work together to establish a metrological basis for the measurement of automotive exhausts. The project is part of the European Metrology Research Programme (EMRP), which is jointly funded by the EMRP participating countries, and the European Union. Two of the four technical work packages aim to establish the metrological base for particle emissions in exhaust gases of diesel vehicles in Europe.

The work package 1 includes the establishment of a particle number standard for soot particles between several hundred and ten thousand particles per cubic centimetre. The aim is to provide calibration services for the end users and industry, in particular for the calibration of

${ }^{\mathrm{a}}$ Corresponding author: hanspeter.andres@metas.ch 
measurement instruments for the type approval of Euro $5 b$ and Euro 6 vehicles (e.g. light vans and passenger cars).

Furthermore in the work package 2 a sound background will be developed for metrological validation of novel instrument types, which measure the soot particle concentrations in exhaust gases from diesel vehicles and prove suitable for the regulatory periodic emission control of vehicles. With the decreasing particle diameters the today's established measuring method of opacity becomes insufficient for accurate legal measurements.

\section{Automotive particle emission metrics}

The regulations UN-ECE R49 and R83 [3,4] for vehicle homologation require particle number concentration measurements in diesel exhaust to be made at certified particle mobility diameters between $23 \mathrm{~nm}$ and $100 \mathrm{~nm}$ and at certified number concentrations between $10^{1} \mathrm{~cm}^{-3}$ and $10^{4} \mathrm{~cm}^{-3}$.

- The entire measuring system consists of a volatile particle remover (VPR) and a specific condensation particle counter (CPC). The calibration of the particle concentration reduction factor (PCRF) of the VPR is done with particle diameters of $30 \mathrm{~nm}$ and $100 \mathrm{~nm}$. Thus, the calibration aerosol for the VPR in the size range $30 \mathrm{~nm}$ to $100 \mathrm{~nm}$ must be thermally stable up to $400{ }^{\circ} \mathrm{C}$.

- The counting efficiency of the CPC must be assessed for mobility diameters of $23 \mathrm{~nm}$ and $41 \mathrm{~nm}$ according to UN-ECE requirements. These small particles contribute significantly to the particle number emissions. Due to the material dependence of the CPC counting efficiency the calibration aerosol should resemble a "soot-like" behaviour.

The project's aim is to establish a standard for particle number and size measurements of automotive particle emissions and build up a network of calibration service providers.

\subsection{Suitable calibration aerosols}

\subsubsection{Temperature stability}

The temperature stability of calibration aerosols of combustion particles, silver and graphite have been studied up to $400{ }^{\circ} \mathrm{C}$.

- The combustion aerosol was generated using a miniCAST (combustion aerosol standard). The miniCAST can be operated either in a fuel-lean or fuelrich combustion mode; the latter presumably producing less thermally stable particles due to the increased volatile organic compounds (VOC) fraction. By using a PALAS thermodenuder thermal stability up to $400{ }^{\circ} \mathrm{C}$ was demonstrated by use of the "golden" VPR from JRC for the more critical fuel-rich combustion mode. The results in the size range $30 \mathrm{~nm}$ to $100 \mathrm{~nm}$ are shown in Table 1 . Thermal stability is good for thermally treated $30 \mathrm{~nm}$ and $50 \mathrm{~nm}$ particles, and still sufficient for $100 \mathrm{~nm}$. The maximal particle number concentration is in the order of $10^{4} \mathrm{~cm}^{-3}$.

- Silver aerosols were generated using a nucleation oven at temperatures up to $1250{ }^{\circ} \mathrm{C}$ with and without a sintering oven operated at $400{ }^{\circ} \mathrm{C}$ downstream. During sintering the nucleated silver particles shrink by $1 \mathrm{~nm}$ to $17 \mathrm{~nm}$ in the size range $15 \mathrm{~nm}$ to $50 \mathrm{~nm}$, respectively. By using a setup with two sintering ovens thermal stability of the sintered silver particles was demonstrated. The achievable maximum silver particle size is limited to $50 \mathrm{~nm}$.

- An aerosol of graphite particles was generated using the PALAS spark generator DNP 3000. Particles in this generator are produced in a spark discharge between two graphite electrodes. By varying the spark frequency and the diluting air flow particle sizes in the range between $20 \mathrm{~nm}$ and $100 \mathrm{~nm}$ are generated. Particle number concentrations up to $10^{7} \mathrm{~cm}^{-3}$ are achievable. The thermal stability of the particles was verified up to $400{ }^{\circ} \mathrm{C}$. Observed particle diameter changes are below $1 \%$.

Table 1. The temperature characteristics of the thermally treated combustion particles are listed.

\begin{tabular}{|c|c|c|}
\hline $\begin{array}{c}\text { Particle } \\
\text { diameter } \\
{[\mathbf{n m}]}\end{array}$ & $\begin{array}{c}\text { Concentration } \\
\text { upstream VPR } \\
{\left[\mathbf{c m}^{-3}\right]}\end{array}$ & $\begin{array}{c}\text { Change in } \\
\text { diameter } \\
{[\mathbf{\%}]}\end{array}$ \\
\hline 30 & $\leq 6^{\prime} 000$ & $-1.3 \pm 0.5$ \\
\hline 50 & $\leq 10^{\prime} 000$ & $-1.4 \pm 0.7$ \\
\hline 100 & $\leq 20^{\prime} 000$ & $-3.4 \pm 0.3$ \\
\hline
\end{tabular}

For all three calibration aerosols thermal stability up to $400{ }^{\circ} \mathrm{C}$ was demonstrated. The calibration aerosol with silver particles is limited by the achievable maximum particle size. The combustion and graphite aerosol prove suitable.

\subsection{2 "Soot-like" behaviour}

The "soot-like" behaviour was subsequently studied by determining the size dependent counting efficiency of a UN-ECE compatible test CPC with a nominal "cut-off" at $23 \mathrm{~nm}$ using combustion aerosol, graphite aerosol or "real soot". The "real soot" was generated with a Daimler V6 HD Engine at the JRC site. The "real soot" was probed either in the CVS (constant volume sampler) tunnel or directly in the exhaust pipe.

The particle number concentrations of size selected aerosols with a particle size of $23 \mathrm{~nm}$ and $41 \mathrm{~nm}$, respectively, were simultaneously measured with the test CPC and a faraday cup electrometer (FCAE TSI 3068B) and/or a standard CPC (TSI 3772). The particle number concentrations for the "real soot" after the thermal treatment turned out to be too low to be measured by the electrometer.

In Table 2 the counting efficiencies of the test $\mathrm{CPC}$ are listed. The counting efficiencies were calculated according to the methods described in draft ISO/DIS 27891.[5] 
Counting efficiencies for the "real soot" could only be determined by calibration against the standard CPC (method CPC), whereas for the combustion and graphite aerosols both calibration methods (methods FCAE and CPC) were applied.

Table 2. Counting efficiencies $E$ according to ISO/DIS 27891

[5] calibration methods FCAE and CPC are shown. For the

"real soot" only data with a Torque of $433 \mathrm{Nm}$ are included. Uncertainties correspond to a $95 \%$ probability $(\mathrm{k}=2)$.

\begin{tabular}{|c|c|c|c|c|}
\hline $\begin{array}{c}\mathbf{d} \\
{[\mathbf{n m}]}\end{array}$ & Aerosol & method & $\begin{array}{c}\boldsymbol{E}[\%] \\
\text { TSI 3772 }\end{array}$ & $\begin{array}{c}\boldsymbol{E}[\%] \\
\text { Test CPC }\end{array}$ \\
\hline 23 & miniCAST & FCAE & $88.2 \pm 2.8$ & $26.5 \pm 0.8$ \\
\hline 23 & graphite & FCAE & $90.7 \pm 2.9$ & $41.4 \pm 2.2$ \\
\hline 23 & miniCAST & CPC & n.A. & $30.0 \pm 1.0$ \\
\hline 23 & graphite & CPC & n.A. & $48.5 \pm 0.8$ \\
\hline 23 & "real soot" & CPC & n.A. & $45.9 \pm 12.7$ \\
\hline UC-ECE requirement & & $\geq 38$ and $\leq 62$ \\
\hline 41 & miniCAST & FCAE & $89.3 \pm 3.0$ & $77.5 \pm 2.2$ \\
\hline 41 & graphite & FCAE & $90.1 \pm 1.8$ & $79.9 \pm 2.0$ \\
\hline 41 & miniCAST & CPC & n.A. & $89.1 \pm 4.9$ \\
\hline 41 & graphite & CPC & n.A. & $93.3 \pm 3.4$ \\
\hline 41 & "real soot" & CPC & n.A. & $89.2 \pm 6.4$ \\
\hline UC-ECE requirement & & \multicolumn{2}{|c|}{$\geq 90$} \\
\hline
\end{tabular}

From the data listed in Table 2 it is evident, that the standard CPC TSI 3772 did not have the expected $100 \%$ counting efficiencies at particle sizes of $23 \mathrm{~nm}$ and $41 \mathrm{~nm}$. Most probably the CPC was not properly adjusted. Yet, resulting counting efficiencies for combustion and graphite particles were the same for the studied particle sizes of $23 \mathrm{~nm}$ and $41 \mathrm{~nm}$.

For the test CPC with a nominal "cut-off" size of 23 $\mathrm{nm}$ counting efficiencies vary considerably. For both methods the counting efficiencies at $23 \mathrm{~nm}$ are statistically different for combustion and graphite aerosols. At a particle size of $41 \mathrm{~nm}$ they agree within their expanded uncertainties.

The determined efficiencies with the "real soot" vary with engine torque and sampling position (data not shown). Differences in the counting efficiencies in the order of $15 \%$ result upon engine performance and sampling position. For an engine torque of $433 \mathrm{Nm}$ the counting efficiencies at $23 \mathrm{~nm}$ and $41 \mathrm{~nm}$ are concordant to those obtained for the graphite aerosol. The counting efficiency for the miniCAST aerosol at $23 \mathrm{~nm}$ is clearly different; whereas agreement is found for particles with a diameter of $41 \mathrm{~nm}$.

The results demonstrate that the sensitivity of the "cutoff" is clearly material dependent. Differences up to $20 \%$ in counting efficiencies at $23 \mathrm{~nm}$ were found; both for the "real soot" at different engine conditions as well as between the different calibration aerosols. Since variations for "real soot" at different engine conditions are in the same order as variations between different candidate calibration aerosols, "soot-likeness" is probably not a suitable criterion for a calibration aerosol. A future workshop together with instrument manufacturer is planed to present the result and to find a consensus on optimum type of calibration aerosol to be recommended.

\subsection{Particle size and number concentration standard}

\subsubsection{SI-traceable electric mobility diameter}

The particle diameter and size distribution of monodisperse and nominally spherical gold, silver and polystyrene latex particles in the size range $20 \mathrm{~nm}$ to 200 $\mathrm{nm}$ were analysed and certified by Atomic Force Microscopy (AFM), Scanning Mobility Particle Sizing (SMPS) and Transmission Scanning Electron Microscopy (TSEM). For reference gold nanoparticles below $100 \mathrm{~nm}$ systematic deviations between the three sizing methods AFM, SMPS and TSEM were observed (see Figure 3).

Figure 3. Differences are plotted for the particle sizing techniques AFM, TSEM and SMPS for reference gold nanoparticles.

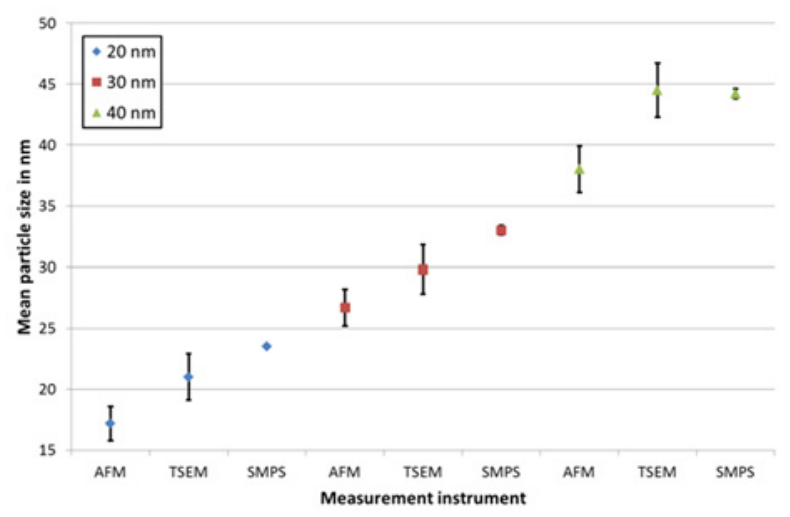

Similar deviations have been reported in the literature [6,7] and could not be resolved in the frame of the project. The JRP-Consortium therefore released the following recommendation on how to calibrate DMAs:

1. The certified size standards shall consist of monodisperse spherical particles normally in a suspension with a certification as a reference material according to ISO Guide 30:1992.[8] The material for the particles shall allow perfect spheres.

2. The certified size standards shall have particle diameters above $80 \mathrm{~nm}$ and the standard deviation of size distribution shall below $5 \%$ of the diameter.

3. The DMA shall be adjusted with at least one certified size standard. The initial calibration of particle sizing is performed according to the relevant equations of ISO 15900.[9] The adjustment of the DMA particle selection is done by changing the high voltage or the sheath air flow. The aerosol flow shall be kept constant during adjustment and subsequent measurement.

4. The particle mobility diameter for particles below 80 $\mathrm{nm}$ is calculated using the equations from ISO 15900 [9] and is assumed to be correct by convention. 


\subsubsection{SI-traceable number concentration}

Traceable calibration services of particle number concentrations have been limited up to now down to particle sizes of $40 \mathrm{~nm}$. To validate the newly developed NMI capabilities for calibration services for particle sizes $<40 \mathrm{~nm}$ two distinct comparisons were or will be conducted, respectively:

- A first comparison to demonstrate comparability of charge concentration measurements by FCAE took place at the Tampere University of Technology. It made use of the university's unique facility to produce singly charged particles over a wide size range. In order to have a worldwide impact, participants from the US (APSL) and Japan (AIST) were invited to the comparison. For singly charged particles in the size range $20 \mathrm{~nm}$ to $100 \mathrm{~nm}$ and number concentrations above $5000 \mathrm{~cm}^{-3}$ participants agree within $3 \%$. Larger deviations are observed at lower particle sizes and concentrations. In Figure 4 the results for a soot aerosol (acetylene burner) with a particle size of $30 \mathrm{~nm}$ are depicted. Due to impaction in the internal sampling line of the FCAE the JRC result is not concordant with the reference value (weighted mean of all participants except JRC).

- A comparison to demonstrate comparability of the number concentration measurements by CPC's will involve several NMIs and manufacturer. The latter will have the possibility to compare their capabilities with NMIs in a parallel round robin test. The calibration aerosol will involve silver and combustion aerosols. The anticipated size range will be between $6 \mathrm{~nm}$ and $100 \mathrm{~nm}$ and number concentration up to $20^{\prime} 000 \mathrm{~cm}^{-3}$.

Figure 4. Comparison results for $30 \mathrm{~nm}$ soot particles and a charge concentration of $10 \mathrm{fC} \mathrm{cm}^{-3}$. The charge concentration corresponds to a particle number concentration of 3800 singly charged particles per $\mathrm{cm}^{3}$. The reference value is the weighted mean of participants except JRC.

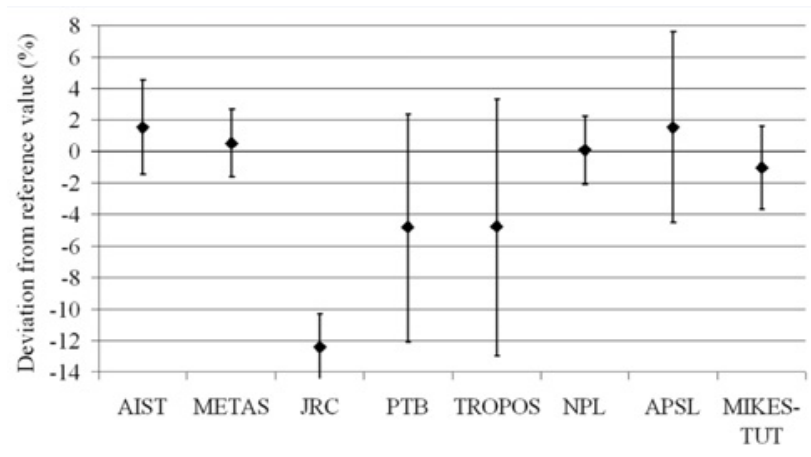

\section{Methods for periodic emission testing}

Since the implementation of emission controls within the roadworthiness testing for motor vehicles, the emission limits for particles in the type approval of diesel motor vehicles have been rigorous reduced from $180 \mathrm{mg} / \mathrm{km}$ (EURO 1, 1993) to $5 \mathrm{mg} / \mathrm{km}$ (EURO 5, 2011). [2]

Due to this current low particle mass concentration requirement the sensitivity of the legal measuring method (opacity) is becoming insufficient for accurate measurement. Therefore, several instruments manufacturer have recently developed prototypes of more sensitive instruments as possible replacements of opacimeters in regulatory periodic emission control of vehicles.

The project's aim is a sound metrological validation of these prototype instrument based on light scattering, electrical, ionisation chamber and diffusion charging sensors. To do so, three national metrology institutes and the Joint Research Centre for Energy and Transport issued common requirements and compared them with current European legislation. Validation work will be conducted at all three national metrology institutes.

\subsection{Common requirements}

The novel instruments will be calibrated for the two measurands opacity and particle number concentration.

- The opacimeter calibration requirements are specified in the European Directive 72/306 EEC [10] as well as in the national requirements for opacimeters. They can be classified in two categories: a) check against smoke or gas of known opacity and b) use of optical density filters representing a particular opacity.

- Particle number concentration calibration requirements are relatively new and not yet widely applied. Requirements for nanoparticle measuring instruments for combustion engines of non-road vehicles can be found in the Swiss regulation SR 941.242.[11] The requirements are "field"-adapted requirements of the UN-ECE R49 and R83 [3,4].

Checks shall be performed over a large range of number concentrations $\left(10^{5}\right.$ to $\left.10^{8} \mathrm{~cm}^{-3}\right)$ and light extinction coefficients $\left(0.01 \mathrm{~m}^{-1}\right.$ to $\left.3.0 \mathrm{~m}^{-1}\right)$ using a range of size distributions typical for light-duty diesel exhaust (particle diameter of 50 to $100 \mathrm{~nm}$ ).

\subsection{Metrological validation}

Manufacturer provided seven prototype instruments for metrological validation. They are based on light scattering (3), electrical (1), ionisation chamber (1) and diffusion charging (2) sensors. These prototype instruments can be divided into two classes; those aimed at replacing regular emission control in garages with increased sensitivity for opacity and those designed for measuring soot exhaust of modern engines with/without diesel particulate filters. The metrological validation is ongoing.

\section{Acknowledgements}

This work was supported by the European Metrology Research Programme (EMRP) jointly funded by the 
EMRP participating countries within EURAMET and the European Union.

\section{References}

[1] "The carcinogenicity of outdoor air pollution" Dana Loomis et al, The Lancet Oncology, 14: 1262 (2013).

[2] Commission Regulation (EC) No 692/2008 of 18 July 2008 implementing and amending Regulation (EC) No 715/2007 of the European Parliament and of the Council on type-approval of motor vehicles with respect to emissions from light passenger and commercial vehicles (Euro 5 and Euro 6) and on access to vehicle repair and maintenance information.

[3] UN/ECE 2013 Regulation No 49, Offic. J. Eur. Union L:171, 1 (2013).

[4] UN/ECE 2012 Regulation No 83, Offic. J. Eur. Union L:42, 1 (2012).

[5] ISO/DIS 27891, Aerosol particle number concentration - Calibration of condensation particle counters (draft version 12, 2013).

[6] "Traceable size determination of nanoparticles, a comparison among European metrology institutes", F. Meli et al, Meas. Sci. Technol. 23: 125005 (2012).

[7] "Size characterization of airborne $\mathrm{SiO}_{2}$ nanoparticles with on-line and off-line measurement techniques: an interlaboratory comparison study", C. Motzkus et al, J Nanopart Res 15:1919 (2013).

[8] ISO Guide 30, Terms and definitions used in connection with reference materials (1992).

[9] ISO 15900, Determination of particle size distribution - Differential electrical mobility analysis for aerosol particles (2009).

[10] COUNCIL DIRECTIVE of 2 August 1972 on the approximation of the laws of the Member States relating to the measures to be taken against the emission of pollutants from diesel engines for use in vehicles.

[11] Ordinance of the Federal Department of Justice and Police from $19^{\text {th }}$ march 2006 on exhaust gas measuring instruments for combustion engines. 